\title{
Braver than we believed, stronger than we knew
}

\author{
Liz Kay \\ Editor, Evidence-Based Dentistry
}

A s so many people have already said, the year that has passed since our last COVID-19 themed issue of Evidence-Based Dentistry has truly been a year like no other, and it is time to take a moment to acknowledge the grief and loss of so many around the world, and, particularly at this time, to consider the enormity of the challenges faced in India and other countries still facing overwhelming numbers of deaths and unquantifiable sadness and illness. But we must also pay tribute to those who have done so much to find ways to protect us, and continue to care for us and for others. This pandemic has frightened us all, but has also proved how much can be achieved when people come together to face, and overcome, challenges they have never met before, and as a result, we shall prevail.

I have personally been astounded by the skill, dedication, and professionalism of the researchers who have worked at a truly remarkable pace to try to help to transform healthcare and dental services so that they cope with the impact of the coronavirus pandemic. Indeed, the whole world has risen to the challenge, and we have made tremendous progress. Mass vaccination has given real hope for the future, but we must remember that we remain in the grip of a global pandemic that has caused more than three million deaths and huge damage to the livelihoods of so many people. Not least, those in dentistry.

Throughout the year, the dedicated staff in dental surgeries have been part of national responses to the pandemic, and have worked through its various stages and lockdowns with quiet dedication and selfless professionalism. They have worked to support individuals and communities, and many have played a part in the implementation of mass vaccination programmes, which have been truly outstanding in their speed of roll out and apparent effectiveness.

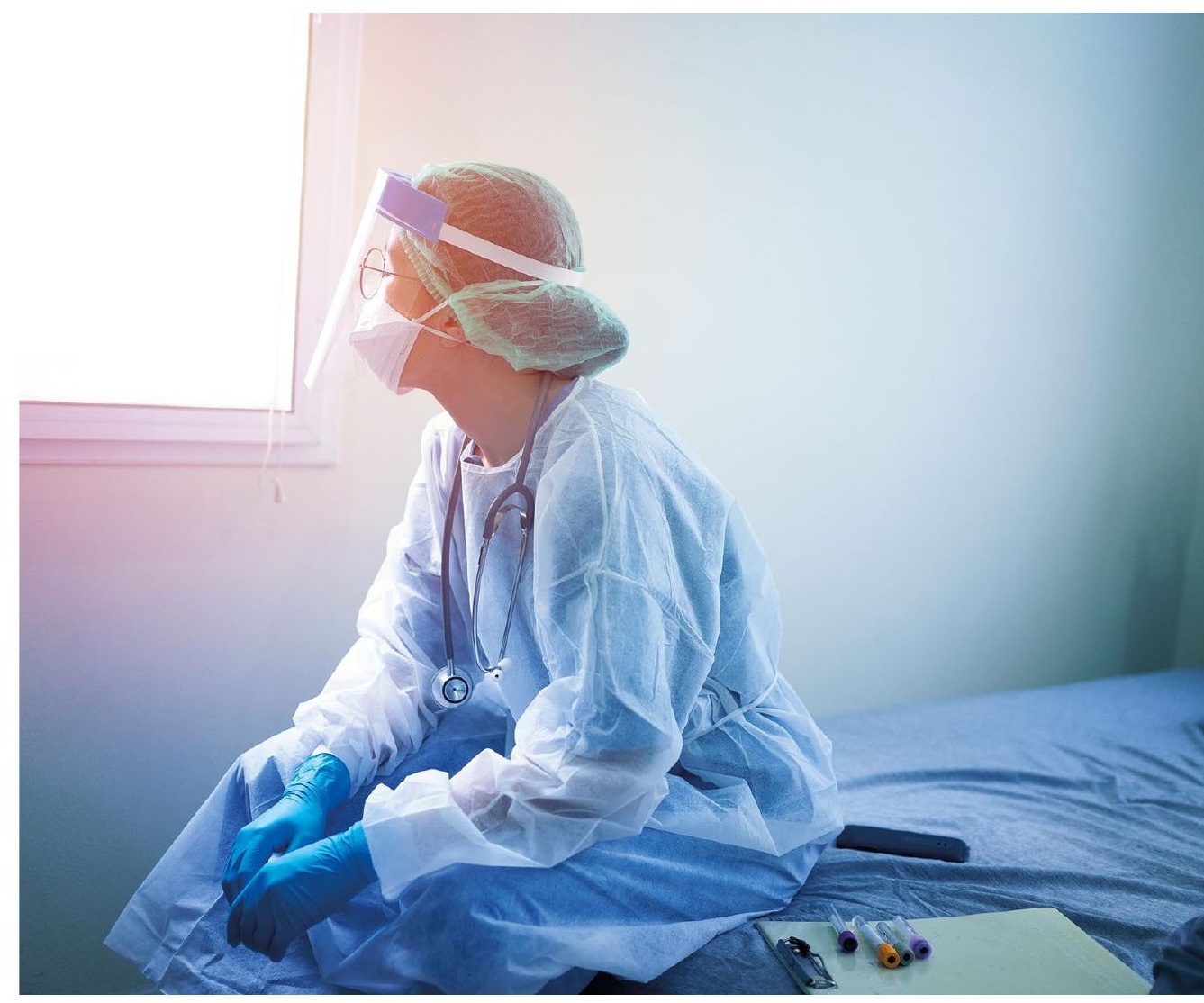

Dental staff who have worked on the frontline have understandably and rightly been the focus of much public praise and gratitude. But their work is only made possible by the many who have done so much to ensure that we quickly learnt of ways to continue to provide services. A clinician can only do their work successfully if the underpinning science is clear, the surgery is run properly, supplies are ordered and patients are cared for and communicated with. People who provide dental care have skillsets which no other profession possesses, and we should all be proud to be part of a service to others during this prolonged period of global crisis, whether we do this through clinical work, research, nursing, technical work or administration. Indeed, witnessing how dental services have adapted to evidence and come through this year has felt extraordinary.

Editorials are an opportunity to look back, but they also provide a moment for us to look to the future. For this generation, at this extraordinary point in history, there has never been a more important time to assess the many challenges that lie ahead of us, and envisage what questions we still need answers to, and exactly what research or analysis we need to undertake in order to provide those answers, so that we can continue to provide oral care for the generations to come, whatever the circumstances. I fervently hope that Evidence-Based Dentistry will play a part in that endeavour.

Evidence-Based Dentistry (2021) 22, 48.

https://doi.org/ 10.1038/s41432-021-0187-x 